\title{
Prediction of resources needed to achieve the national target for treatment of renal failure
}

\author{
I T WOOD, N P MALLICK, A J WING
}

\begin{abstract}
A model of the treatment of end stage renal failure has been primed with observed survival statistics and used to predict the steady state that will be achieved when the present annual target of at least $\mathbf{4 0}$ new patients per million population is in equilibrium with the death rate. The number of patients expected to receive each type of dialysis or a transplant is given per million of population. The personnel and facilities required to care for these patients and the costs of each programme were derived using analyses of workloads and costs in the North Western Regional Health Authority. The study has documented the considerable need for "back up" beds for patients on dialysis who require temporary care as inpatients.

The cost effectiveness of transplantation has been demonstrated; at steady state it is calculated that each successful graft saves the service $£ 30000$. Implementation of the minister's minimum target requires a build up to some three times the resources currently allocated, with parallel increases in numbers of medical, nursing, and other essential staff.
\end{abstract}

Crewe and Alsager College of Higher Education, Crewe I T WOOD, PHD, senior lecturer

Department of Renal Medicine, Manchester Royal Infirmary, Manchester N P MALLICK, MB, FRCP, consultant physician

Renal Unit, St Thomas's Hospital, London

A J WING, DM, FRCP, consultant physician

On behalf of the Renal Association subcommittee on facilities for the treatment of chronic renal failure. Members: M McGeown, chairman; J D Briggs, T Feest, N P Mallick, J Michael, C S Ogg, D G Williams, A J Wing.

Correspondence to: Dr Mary McGeown, Renal Unit, Belfast City Hospital, Belfast BT9 7AB.

\section{Introduction}

On 20 December $1984 \mathrm{Mr}$ John Patten, then parliamentary secretary for health, announced that regional health authorities in England and Wales had been set a target of accepting at least 40 new patients with renal disease per million population by $1987 .{ }^{1}$ It appears that this target is the beginning of an incremental scale since the minister stated that it was "the government's intention that the provision of renal services will continue to expand after 1987." The target for Wales is 50 patients per million population. ${ }^{2}$

Some regions had reached the target by the close of 1984, but most fell short (table I). In all regions the need for planning was accepted in order that sufficient resources and personnel were allocated. Several regions have been interested in the use of mathematical models to predict the numbers of patients with end

TABLE I-Acceptance of new patients per million population (pmp) in each regional health authority during 1979 and 1984 and intake rates of high risk (aged over 55 years or diabetic) patients

\begin{tabular}{|c|c|c|c|c|c|}
\hline \multirow{2}{*}{$\begin{array}{c}\text { Regional } \\
\text { health authority }\end{array}$} & \multirow{2}{*}{$\begin{array}{l}\text { Population } \\
\text { (millions) }\end{array}$} & \multicolumn{2}{|c|}{$\begin{array}{c}\text { Total No of patients } \\
\text { (pmp) }\end{array}$} & \multicolumn{2}{|c|}{$\begin{array}{c}\text { No of high risk patients } \\
\text { (pmp) }\end{array}$} \\
\hline & & 1979 & 1984 & 1979 & 1984 \\
\hline East Anglia & 1.9 & $35 \cdot 3$ & $38 \cdot 9$ & $12 \cdot 1$ & $17 \cdot 9$ \\
\hline Mersey & $2 \cdot 4$ & $18 \cdot 3$ & $30 \cdot 4$ & 6.7 & $13 \cdot 8$ \\
\hline Northern & $3 \cdot 1$ & $32 \cdot 9$ & $40 \cdot 3$ & $10 \cdot 3$ & $22 \cdot 3$ \\
\hline North Western & $4 \cdot 0$ & $15 \cdot 0$ & $30 \cdot 4$ & 0.8 & $13 \cdot 0$ \\
\hline Oxford & $2 \cdot 4$ & $22 \cdot 1$ & $36 \cdot 7$ & $1 \cdot 3$ & $20 \cdot 0$ \\
\hline South Western & $3 \cdot 1$ & $22 \cdot 6$ & $32 \cdot 3$ & $5 \cdot 5$ & $14 \cdot 5$ \\
\hline North East Thames & $3 \cdot 7$ & $26 \cdot 5$ & $29 \cdot 7$ & $4 \cdot 1$ & $11 \cdot 1$ \\
\hline North West Thames & $3 \cdot 5$ & $21 \cdot 1$ & $29 \cdot 7$ & $4 \cdot 0$ & $15 \cdot 1$ \\
\hline South East Thames & $3 \cdot 6$ & $43 \cdot 3$ & $44 \cdot 71$ & $12 \cdot 2$ & $22 \cdot 8$ \\
\hline South West Thames & $2 \cdot 9$ & $7 \cdot 2$ & $25 \cdot 5$ & $3 \cdot 1$ & 14.5 \\
\hline Trent & $4 \cdot 6$ & $20 \cdot 4$ & $40 \cdot 4$ & $5 \cdot 4$ & $18 \cdot 7$ \\
\hline Wales & $2 \cdot 8$ & $18 \cdot 6$ & $34 \cdot 3$ & $6 \cdot 8$ & $15 \cdot 4$ \\
\hline Wessex & $2 \cdot 8$ & $13 \cdot 6$ & $27 \cdot 5$ & $2 \cdot 1$ & $12 \cdot 5$ \\
\hline West Midlands & $5 \cdot 2$ & $17 \cdot 7$ & $26 \cdot 0$ & 1.7 & $12 \cdot 5$ \\
\hline Yorkshire & 3.6 & 18.9 & $33 \cdot 1$ & $3 \cdot 1$ & $15 \cdot 5$ \\
\hline
\end{tabular}


TABLE II-Number of patients (per million population) receiving different types of treatment in each region in England and Wales on 31 December 1979 and 1984

\begin{tabular}{|c|c|c|c|c|c|c|c|c|c|c|}
\hline \multirow[b]{3}{*}{ Regional health authority } & \multicolumn{5}{|c|}{1979} & \multicolumn{5}{|c|}{1984} \\
\hline & \multirow{2}{*}{$\begin{array}{c}\text { Total } \\
\text { No of } \\
\text { patients }\end{array}$} & \multicolumn{4}{|c|}{ Type of treatment } & \multirow{2}{*}{$\begin{array}{c}\text { Total } \\
\text { No of } \\
\text { patients }\end{array}$} & \multicolumn{4}{|c|}{ Type of treatment } \\
\hline & & $\begin{array}{c}\text { Hospital } \\
\text { haemodialysis }\end{array}$ & $\begin{array}{c}\text { Home } \\
\text { haemodialysis }\end{array}$ & $\begin{array}{c}\text { Peritoneal } \\
\text { dialysis }\end{array}$ & Graft & & $\begin{array}{c}\text { Hospital } \\
\text { haemodialysis }\end{array}$ & $\begin{array}{c}\text { Home } \\
\text { haemodialysis }\end{array}$ & $\begin{array}{c}\text { Peritoneal } \\
\text { dialysis }\end{array}$ & Graft \\
\hline $\begin{array}{l}\text { East Anglia } \\
\text { Mersey } \\
\text { Northern } \\
\text { North Western } \\
\text { Oxford } \\
\text { South Western } \\
\text { North East Thames } \\
\text { North West Thames } \\
\text { South East Thames } \\
\text { South West Thames } \\
\text { Trent } \\
\text { Wales } \\
\text { Wessex } \\
\text { West Midlands } \\
\text { Yorkshire }\end{array}$ & $\begin{array}{r}144 \cdot 7 \\
107 \cdot 5 \\
140 \cdot 3 \\
75 \cdot 3 \\
118 \cdot 3 \\
110 \cdot 0 \\
167 \cdot 0 \\
124 \cdot 0 \\
202 \cdot 8 \\
27 \cdot 6 \\
108 \cdot 5 \\
101 \cdot 1 \\
59 \cdot 3 \\
77 \cdot 5 \\
79 \cdot 4\end{array}$ & $\begin{array}{r}30 \cdot 0 \\
19 \cdot 6 \\
41 \cdot 6 \\
11 \cdot 8 \\
15 \cdot 8 \\
18 \cdot 1 \\
22 \cdot 4 \\
18 \cdot 0 \\
37 \cdot 5 \\
5 \cdot 9 \\
16 \cdot 7 \\
10 \cdot 4 \\
3.9 \\
17 \cdot 1 \\
24 \cdot 4\end{array}$ & $\begin{array}{l}27 \cdot 4 \\
38 \cdot 8 \\
24 \cdot 2 \\
25 \cdot 0 \\
42 \cdot 9 \\
51 \cdot 6 \\
68 \cdot 1 \\
39 \cdot 7 \\
54 \cdot 2 \\
12 \cdot 4 \\
56 \cdot 1 \\
40 \cdot 4 \\
27 \cdot 9 \\
19 \cdot 2 \\
25 \cdot 6\end{array}$ & $\begin{array}{r}1 \cdot 6 \\
9 \cdot 2 \\
13 \cdot 2 \\
1 \cdot 5 \\
3 \cdot 3 \\
6 \cdot 8 \\
11 \cdot 6 \\
2 \cdot 3 \\
3 \cdot 1 \\
0 \cdot 3 \\
4 \cdot 1 \\
4 \cdot 3 \\
0 \\
1 \cdot 2 \\
2 \cdot 8\end{array}$ & $\begin{array}{r}85 \cdot 8 \\
40 \cdot 0 \\
61 \cdot 3 \\
37 \cdot 0 \\
56 \cdot 3 \\
33 \cdot 5 \\
64 \cdot 9 \\
64 \cdot 0 \\
108 \cdot 1 \\
9 \cdot 0 \\
31 \cdot 5 \\
46 \cdot 1 \\
27 \cdot 5 \\
40 \cdot 0 \\
26 \cdot 7\end{array}$ & $\begin{array}{l}244 \cdot 2 \\
186 \cdot 7 \\
231 \cdot 9 \\
174 \cdot 3 \\
214 \cdot 2 \\
185 \cdot 2 \\
269 \cdot 5 \\
180 \cdot 6 \\
318 \cdot 3 \\
71 \cdot 0 \\
205 \cdot 4 \\
168 \cdot 6 \\
132 \cdot 5 \\
159 \cdot 6 \\
156 \cdot 1\end{array}$ & $\begin{array}{l}57 \cdot 9 \\
38 \cdot 8 \\
58 \cdot 2 \\
24 \cdot 8 \\
23 \cdot 8 \\
20 \cdot 6 \\
36 \cdot 2 \\
25 \cdot 4 \\
43 \cdot 3 \\
9 \cdot 7 \\
29 \cdot 6 \\
15 \cdot 0 \\
11 \cdot 1 \\
26 \cdot 3 \\
31 \cdot 1\end{array}$ & $\begin{array}{l}29 \cdot 5 \\
27 \cdot 1 \\
31 \cdot 9 \\
41 \cdot 0 \\
52 \cdot 9 \\
52 \cdot 9 \\
61 \cdot 1 \\
35 \cdot 7 \\
44 \cdot 2 \\
9 \cdot 0 \\
53 \cdot 9 \\
36 \cdot 1 \\
21 \cdot 1 \\
27 \cdot 3 \\
30 \cdot 0\end{array}$ & $\begin{array}{r}3 \cdot 7 \\
18 \cdot 8 \\
59 \cdot 0 \\
35 \cdot 3 \\
24 \cdot 2 \\
33 \cdot 2 \\
51 \cdot 4 \\
25 \cdot 1 \\
37 \cdot 8 \\
20 \cdot 7 \\
47 \cdot 4 \\
30 \cdot 0 \\
27 \cdot 9 \\
33 \cdot 1 \\
35 \cdot 8\end{array}$ & $\begin{array}{r}153 \cdot 2 \\
102 \cdot 1 \\
92 \cdot 9 \\
73 \cdot 3 \\
113 \cdot 3 \\
78 \cdot 4 \\
120 \cdot 8 \\
94 \cdot 3 \\
193 \cdot 1 \\
31 \cdot 7 \\
74 \cdot 6 \\
87 \cdot 5 \\
72 \cdot 5 \\
72 \cdot 9 \\
59 \cdot 2\end{array}$ \\
\hline
\end{tabular}

stage renal failure receiving various forms of dialysis or transplanted and thus to project the facilities and staff that will be necessary to care for them. Three types of models have been used: (i) simple probability models ${ }^{3}$; (ii) Markov chain models; ; and (iii) simulation models. ${ }^{5}$

Models that demonstrate short term trends require priming with the current number of patients receiving each type of treatment. Models that aim at a steady state solution (when the acceptance rate is in equilibrium with the death rate) require long term survival data and assume that the eventual pattern of treatment is stable.

At present the balance between the number of patients on different forms of dialysis and the number who have received a transplant varies between the regions (table II); in particular, the contribution of continuous ambulatory peritoneal dialysis still shows striking differences. It seems likely, however, that regional patterns will converge, with a growing proportion of patients kept alive by functioning transplants and a predictable spread of patients receiving each of the methods of dialysis. Hospital haemodialysis, home haemodialysis, and continuous ambulatory peritoneal dialysis make an almost equal contribution to the national programme (fig 1), but the last is a relatively recent treatment. Furthermore, cyclosporin has been introduced generally into transplantation only

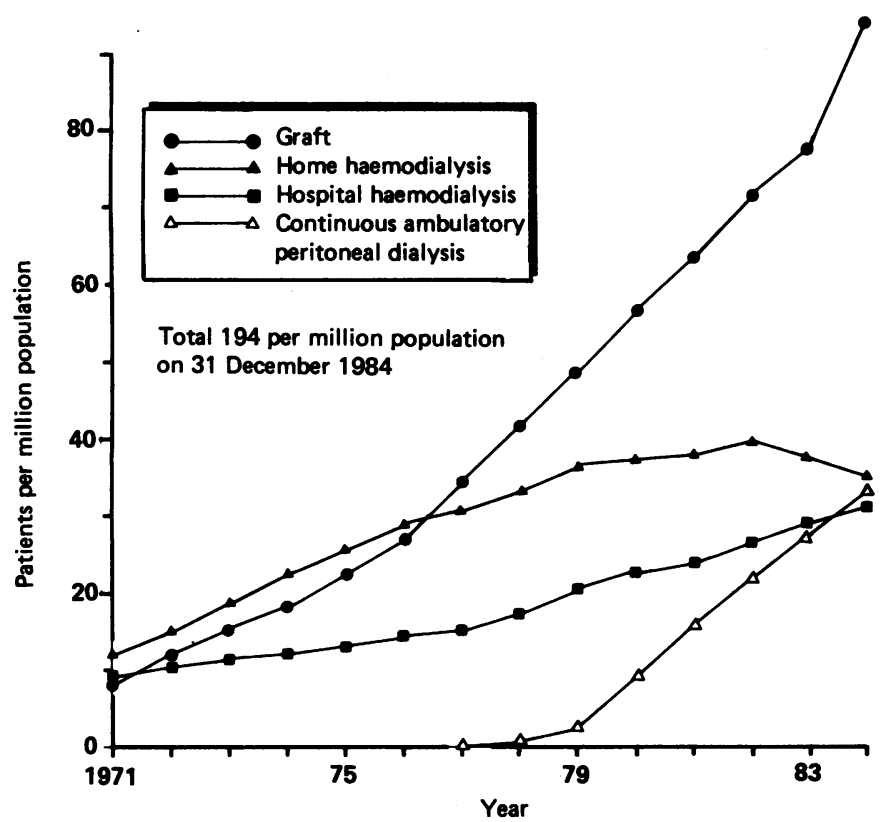

FIG 1-Number of patients per million population receiving each type of treatment in England and Wales, 31 December 1974 to 1984. since 1982. The selection of patients for treatment is becoming more liberal with the inclusion of "high risk" patients-for example, elderly or diabetic patients - who have been shown to benefit from appropriate treatment but for whom treatment choices are less flexible and survival poor.

We report on the application of an updated version of the Manchester model ${ }^{6}$ for the prediction of "norm" of resources and personnel that will be required nationally when, with the acceptance of 40 new patients per million population per year, a steady state has been attained.

\section{Methods and results}

The Manchester model ${ }^{6}$ was designed to predict the level of resources required in the North Western Regional Health Authority. For this paper the model was primed with survival data recorded by the European Dialysis and Transplant Association-European Renal Association Registry. ${ }^{7}$ It uses the flow graph method to give the solution directly, thus relaxing some of the assumptions of the Markov chain and the need to generate year by year figures. Sensitivity analysis can be used to test the robustness of the model to variations in the input parameters.

The model recognises three different patient groups: $(a)$ fit for transplantation, suitable for independent (home or minimal care) dialysis; $(b)$ fit for transplantation, suitable for dependent (hospital) dialysis only; ( $c$ ) not fit for transplantation. Demographic studies performed in the early 1970s suggested that about 35 new patients per million population aged under 55 would require treatment. ${ }^{8-10}$ This incidence was considered to represent the number of standard risk patients. It is widely accepted now, however, that the treatment of high risk patients-namely, those over 55 or those with diabetes or other coincidental diseases-is necessary.

For the present study of national needs the annual intake of patients included patients at standard risk and at high risk, and the model was adjusted so that at the time of presentation the groups were subdivided as follows: of standard risk patients, $80 \%$ are considered to be suitable for a transplant and $70 \%$ are considered suitable for independent dialysis; a 10 day "back up" period in hospital stay yearly is assumed for complications of dialysis or intercurrent illness. The corresponding figures for the high risk category are: $60 \%$ suitable for a transplant; $30 \%$ suitable for independent dialysis; 20 days' hospital back up. The proportion of patients considered suitable for a transplant or otherwise was arrived at after consideration of the proportion of patients being treated for end stage renal failure who are placed on the waiting list at UK Transplant and the proportion of these who were classified as "active" (available for transplantation) at any one time. Hospital back up days were determined by reviewing data from the North Western region and other regions.

Importantly, the model is not restrained by the availability of grafts. It is assumed that sufficient grafts will be available to carry out the number of transplant operations needed to maintain steady state. On any other calculation dialysis numbers would be greatly increased.

For the purposes of the model high risk patients contribute five new patients out of an intake of 40 per million population, 15 out of an intake of 50 per million, and 25 out of an intake of 60 per million. The observed rates 
of standard risk and high risk patients who began treatment in each of the regions in 1979 and 1984 may be derived from table $I$.

Continuous ambulatory peritoneal dialysis has not been considered separately. The model accounts for this treatment as a substitute for independent home haemodialysis, for which running costs are similar. Some patients are treated by continuous peritoneal dialysis who would otherwise require supported haemodialysis, but it is assumed that at steady state the number will not be large enough to distort the model seriously.

Survival analyses on the UK database showed that mean life expectancy in standard risk patients was approximately $11^{1 / 2}$ years and in high risk patients six years. Our model incorporates refined subsets of these data and also a "natural" mortality factor to account for the reduced natural life span of older patients. Patients who changed treatment were considered lost to observation from the date of the change so that the life expectancy for each type of treatment is stated separately. The reduced life expectancies for the "failed graft" patient allow for the time he or she will have spent with a successful transplant. It was necessary to extrapolate beyond the length of the 10 year survival analyses to reach mean survival points, so our life expectancy calculations (table III) necessarily rely on data that are up to 10 years old. They must be underestimates because of improvements

\begin{abstract}
TABLE III-Life expectancy in months according to method of treatment, derived from the European Dialysis and Transplant Association Registry survival analyses for standard and high risk patients. (Figures in parentheses are life expectancy for patients with a failed gaft who are returned to dialysis)
\end{abstract}

\begin{tabular}{lc}
\hline & Life expectancy (months) \\
\hline Standard risk: & $139(112)$ \\
Independent dialysis & 111 \\
Successful transplant & $100(77)$ \\
Hospital dialysis & $84(64)$ \\
High risk: & $81(38)$ \\
Independent dialysis & $55(38)$ \\
Successful transplant & \\
Hospital dialysis & \\
\hline
\end{tabular}

TABLE IV-Model prediction of numbers of patients per million population (pmp) receiving each type of treatment when the intake of 40 new patients pmp per year results in a steady state

\begin{tabular}{lcc}
\hline & $\begin{array}{c}\text { For 35 standard risk } \\
\text { patients } \\
\text { (pmp) }\end{array}$ & $\begin{array}{c}\text { For five high risk } \\
\text { patients } \\
\text { (pmp) }\end{array}$ \\
\hline Functioning transplant & 185.9 & 11.0 \\
Independent dialysis: & 161.2 & $7 \cdot 1$ \\
$\quad$ At home & $6 \cdot 1$ & 0.4 \\
$\quad$ In training & $51 \cdot 1$ & 11.5 \\
Hospital dialysis & 5.3 & 0.8 \\
Inpatient: & 2.9 & 0.2 \\
$\quad$ Dialysis back up & 412.5 & 31.0 \\
For transplantation or its complications & & \\
\hline
\end{tabular}

Note: $9 \cdot 2$ inpatient beds are required pmp for intercurrent problems in dialysis and transplant patients. The initial stay for transplantation is included; inpatient beds for patients in training for continuous ambulatory peritoneal dialysis are not included. These will be roughly two beds pmp so the overall inpatient bed requirement for end stage renal failure is approximately 11 pmp, or about 45 beds for a region of four million people.

in treatment, including the recent introduction of cyclosporin for immunosuppression after transplantation; but from observations of the likely order of improvement that is occurring it appears that the model is robust enough not to be seriously distorted.

Table IV shows the number of patients in each treatment mode at steady state. The hitherto unquantified, but considerable, requirement for inpatient beds to back up the dialysis and transplantation services is documented. These beds need nursing and junior medical staff cover in addition to the staffing needs for the management of end stage renal failure by dialysis and transplantation, which are estimated in table V.

Figure 2 and table VI give the costs of the programme. These take into account death rates and graft failures. Costs were kept at 1982 levels to allow comparison with other published data, ${ }^{11}$ except that drug costs for graft maintenance are $£ 175$ a month to cover the use of cyclosporin rather than azathioprine.

\section{Standard risk patients per million population}

£ 2793 million

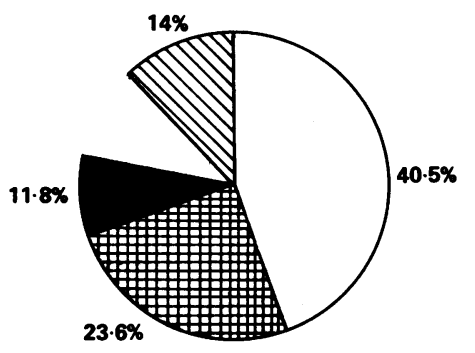

$23.6 \%$
5 High risk patients per million population

f $\mathbf{2 7 8}$ million

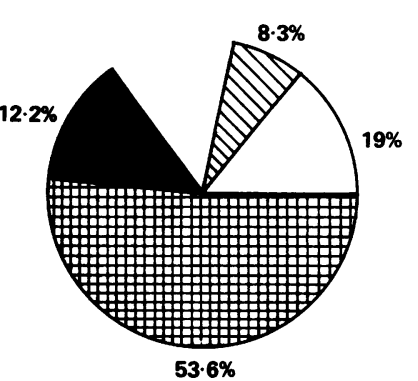

Successful transplant

Independent dialysis

Dependent (hospital or centre) dialysis

Inpatient (for intercurrent illness or complication while on dialysis, for transplantation or for posttransplantation problems)

The unfilled arc represents the cost of equipment and of home modification for independent dialysis

FIG 2 - Costs incurred in treating 35 standard risk patients and five high risk patients per million population at 1982 prices (percentages).

TABLE V-Model predictions of numbers of staff required per million population to care for numbers of dialysis patients at steady state

\begin{tabular}{lc}
\hline \multicolumn{1}{c}{ Personnel (whole time equivalents) } & No \\
\hline Consultant physicians & 2 \\
Consultant surgeon & $0 \cdot 3$ \\
Registrars or senior house officers & 2 \\
Clinical assistant & 2 \\
Nurses & 24 \\
Technicians & 4 \\
Domestics & 2 \\
Secretaries & 2 \\
Ward clerks & 2 \\
Dietitians & 2 \\
Social workers & 1 \\
\end{tabular}

Note: This staffing covers 16 "renal unit" dialysis stations on a one week, two shift, six day basis. It allows $10 \%$ space for "ill" patients, temporary dialysis for continuous ambulatory patients, temporary dialysis for continuous ambulatory
peritoneal dialysis, or independent dialysis complications; it peritoneal dialysis, or independent dialysis complications; it
provides for a million population at 40 new patients ( 35 standard risk and five high risk) a year. The nursing and technical staffing covers the supervision of home dialysis patients both in training and at home. The workload includes over 400 patients at home (see table IV).

The secretarial help covers all requirements of the medical and nursing staff for inpatients, outpatients, and unit record keeping. Staffing for acute renal failure, transplantation, kenera. Staffict general nephrology work, and inpatient back up are not
included in these requirements.

TABLE VI-Model predictions of annual costs per patient according to risk category and group in steady state at 1982 prices

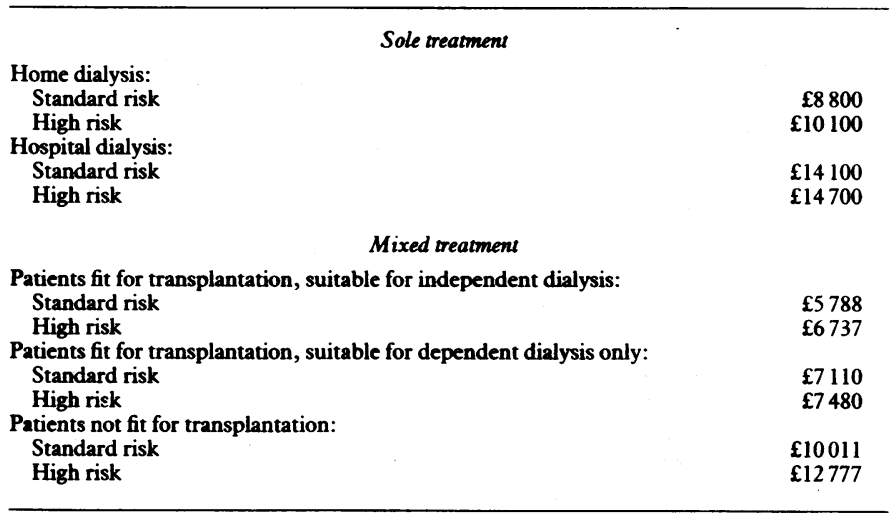




\section{Discussion}

Our approach describes the steady state stage of numbers of patients and use of resources in the treatment of renal failure. Any model may become less stable if there are new treatments. The introduction of continuous ambulatory peritoneal dialysis and the improvements in transplantation coincident with the introduction of cyclosporin have made a big impact on the pattern of treatment for end stage renal failure and established fresh momenta in the system. Our model is built on current knowledge and observed results, and we believe that our calculations of the impact of continuous ambulatory peritoneal dialysis and of cyclosporin on graft survival will suffice for the model to represent adequately the likely outcome.

There are many approaches to assessing cost: "total," "average," "marginal," and "worths." We believe that the most important measure is the overall cost of treating a mix of patients by an integrated programme of different treatments. Treatment for renal failure does not lend itself to a choice of alternative treatments on economic grounds alone. The changing medical and social needs of the patient dictate the treatment pattern. There is one choice only: to treat or not to treat.

Our analyses are based on an assumption of the fulfilment of a national target of treating 40 new patients per million population per year with end stage renal failure, equivalent to 1982 patients for England and Wales. We have made no allowance for the spare capacity that exists in all systems if they are to work effectively. Hospital haemodialysis is provided on a planned basis and can operate at high utilisation rates, but any attempt to operate a dialysis unit full out round the clock imposes impossibly high demands ${ }^{12}$ and can be dangerous. The cost of operating the transplant unit represents a small part of the total (some 5\%) so the assumption of full bed occupancy here makes little difference to the actual costs. Staff overheads are determined by the need to provide for dialysis and transplantation and also to support the use of back up beds for intercurrent problems. The lower cost of achieving outpatient status with continuous ambulatory peritoneal dialysis compared to home haemodialysis must be weighed against the higher cost of readmission for intercurrent care.

The national model predicts an expenditure of $£ 3 \cdot 1 \mathrm{~m}$ per million population at a steady state resulting from an intake of 40 new patients per million population per year. Any increase in this intake means more high risk patients. The corresponding figures are $£ 3.6 \mathrm{~m}$ and $£ 4.2 \mathrm{~m}$ for intakes of 50 and 60 new patients with a mix of standard and high risk category patients as given above. Dowie estimated that the annual expenditure was $£ 1 \mathrm{~m}$ per million population in England and Wales in $1981-2 .{ }^{13}$ It appears that regional health authorities will have to budget for a considerable rise in costs for the treatment of end stage renal failure over the next few years as more patients are accepted into the programme, building up towards the steady state.

Table VI gives the average annual cost per patient group. Since most patients are managed by a sequence of treatments, average annual costs for one treatment only are of limited value. Nevertheless, they show the differences in cost of the different types of treatments and allow immediate comparison with Mancini's average figures of $£ 11200$ to $£ 13650$ for hospital haemodialysis and $£ 7100$ to $£ 8700$ for home dialysis at November 1981 prices $^{11}$-a time when few high risk patients were treated.

Any improvement in survival increases the overall cost of the programme by the need for more drugs, disposable and fixed equipment, and back up services. A one month improvement in life expectancy with hospital haemodialysis treatment increased the programme cost by roughly six times as much as a similar increase in graft survival. Thus the model points to the primary role that transplantation must have in the strategy of regional programmes and emphasises that this reduces the overall cost of the programme by about $£ 30000$ for each successful transplant.

These predictions should help to establish a minimum requirement of facilities and personnel to fulfil the national target for the treatment of end stage renal failure. The resource implications are considerable, but it must be remembered that 16 European countries accepted over $\mathbf{4 0}$ new patients per million population in $1984 .^{7}$ In each of these countries the patient with end stage renal failure already had a better chance in 1984 than it is hoped he or she will have in England and Wales by 1987.

\section{References}

1 Patten J. Kidney patients. House of Commons Official Report (Hansard) 1984 Dec 20;710:cols 309-10

2 Edwards N. Kidney patients. House of Commons Official Repont (Hansard) 1983 Dec 5;710:col 23. 3 Pincherle G. Services for patients with chronic renal failure in England and Wales. Health Trends 1977;9:41-4.

4 Davies R, Jahnson DB, Farrow SC. Planning patient care with a Markov model. Operational Research Quarterly 1975;26:599-607.

South East Thames Regional Health Authority. Adult renal services. Hastings: SETRHA, 1966.

6 Wood IT, Mallick NP, Moores B. A flexible model for planning facilities for patients with end-stage renal failure. BrMed $\mathcal{J}$ 1980;281:575-7.

7 Brunner FP, Broyer M, Brynger H, et al. Combined report on regular dialysis and transplantation in Europe XV, 1984. Proc Eur Dial Transplant Assoc 1985;22:31-95.

8 Branch RA, Clarke GW, Cochrane AL, Jones JH, Scarborough H. Incidence of uraemia and requirements for maintenance haemodialysis. $\mathrm{Br}$ Med $\mathrm{J} 1971$; $\mathrm{i}: 249-54$.

9 Pendreigh DM, Howitt LF, MacDougall AI, et al. Survey of chronic renal failure in Scotland. Lancet 1972; i:304-7.

10 McGeown MG. Chronic renal failure in Northern Ireland 1968-70. Lancet 1972;ii:307-10.

11 Mancini PV. The costs of treating end-stage renal failure. London: Economic Advisers' Office, Department of Health and Social Security, June 1984.

2 Davison AM, Reed DJ, Levins AM. Under-utilized hospital haemodialysis resources. Lance 1984;i: 723-5.

13 Dowie $R$. Development of resources in treatment of end-stage renal failure in England and Wales. BrMed f 1984;288:988-91.

(Accepted 27 February 1987)

\section{MATERIA NON MEDICA}

\section{Innocent tyranny?}

Often we used to wonder why he so proudly caressed his long, greyish beard while talking to everyone. He was hale and hearty at 59 years, and now and then we saw him with the surgery chief but only lately realised that he was hiding a large goitre underneath his beard. He was persuaded to undergo surgery and was admitted.

At the preoperative preparation he vehemently refused to part with the almost age long association with his beard. We were amused and scornful. The chief was called, with whom he could not argue. But his clean shaven face only made his dejection more obvious. He looked into the mirror, sighed, and was silent after that. Over the next few minutes he complained of severe chest pain and collapsed. All resuscitative measures failed.

While signing the death certificates I wondered if thyroid surgery could be done with the beard on; but then so many bearded men have been shaved before operations. We understood that he liked his beard but how were we to know that he valued it so much that he'd die? Were we, or were we not guilty of an offence? The barber seemed to share our guilt.-SHYAM S KOTHARI, JESURAJ LIONEL, Vellore, India.

\section{Strict quarantine}

When I was 11 in $1920 \mathrm{I}$ had chickenpox-very badly.

"Whatever you do, don't let your little sister come past the door," they $N$ said to me. And I didn't.

For the first day or two there was no temptation, I felt so rotten. But as time went by I asked for the door of my bedroom to be left open so that I $\mathrm{N}$ could hear what was going on in the house, and that allowed lovely conversations with my 6 year old sister when no one was around to see. But I never let her past the door.

Adults came to see me and they got in. Some of them brought presents. Grandpa brought me a silver threepenny bit. Wealth! But no freedom to go shopping.... A problem easily solved.

I summoned my sister when the coast was clear and transferred the coin from my hot and sticky hand to hers. But I never allowed her over the threshold. Then I sent her off to the sweetie shop with strict instructions as to what I required. When she got back I recompensed her for her trouble. I counted out 12 aniseed balls, tore a strip off the liquorice strap, and divided the bag of popcorn in two. These delights I pressed into her eager outstretched palm at the doorway. But I didn't let her in.

And she didn't take chickenpox. So the quarantine instructions must have been quite right.—MURIEL J F BARNETT, Edinburgh. , 